\title{
The impact of an integrated community-based micronutrient and health programme on anaemia in non-pregnant Malawian women
}

\author{
Alexander A Kalimbira ${ }^{1}$, Carolyn MacDonald ${ }^{2}$ and Janis Randall Simpson ${ }^{3, *}$ \\ 'Department of Home Economics and Human Nutrition, Bunda College of Agriculture, University of Malawi, \\ Lilongwe, Malawi: ${ }^{2}$ World Vision Canada, Mississauga, Ontario, Canada: ${ }^{3}$ Department of Family Relations and \\ Applied Nutrition, University of Guelph, Guelph, Ontario, N1G 2W1, Canada
}

Submitted 19 August 2008: Accepted 15 September 2009: First published online 5 November 2009

\begin{abstract}
Objective: To assess the impact of an integrated community-based micronutrient and health $(\mathrm{MICAH})$ programme on anaemia $(\mathrm{Hb}<120 \mathrm{~g} / \mathrm{l})$ among non-pregnant rural Malawian women aged 15-49 years from communities that participated in the 1996-2005 MICAH programme.

Design: Prospective study of two large-scale cross-sectional surveys conducted in 2000 and 2004 as part of programme evaluation in MICAH and Comparison areas. Setting: Rural areas across Malawi. The MICAH programme implemented a comprehensive package of interventions to reduce anaemia, based on a broad range on direct and indirect causes in Malawi. The project approaches included: Fe supplementation; dietary diversification and modification; food fortification; and strengthening primary health care.

Participants: Non-pregnant women of childbearing age (15-49 years old, $n$ 5422), from randomly selected households that responded to a household questionnaire, had their $\mathrm{Hb}$ measured from finger-prick blood samples using the HemoCue ${ }^{\circledR}$.

Results: In 2000, there was no significant difference in $\mathrm{Hb}$ concentration between MICAH and Comparison areas (mean (SE): 117.4 (0.4) v. 116.8 (0.5) g/l, $P>0 \cdot 05$ ) and the corresponding prevalence of anaemia (53.5\% v. 52.9\%, $P>0 \cdot 05)$. By 2004, $\mathrm{Hb}$ concentration had increased significantly in MICAH but not in Comparison areas (mean (SE): $121 \cdot 0(0 \cdot 4) v .115 \cdot 7(0 \cdot 6) \mathrm{g} / 1, P<0 \cdot 001)$, and the prevalence of anaemia had declined significantly in MICAH areas $\left(53.5 \%\right.$ to $\left.44 \cdot 1 \%, \chi^{2}=28 \cdot 2, P<0 \cdot 0001\right)$ but not in Comparison areas $\left(52 \cdot 8 \%\right.$ to $\left.54 \cdot 0 \%, \chi^{2}=0 \cdot 3, P=0 \cdot 6\right)$.

Conclusions: The MICAH programme was an effective public health nutrition programme that was associated with significant reductions in the prevalence of anaemia among non-pregnant rural Malawian women.
\end{abstract}

Anaemia $(\mathrm{Hb}<120 \mathrm{~g} / \mathrm{l})$ is a significant public health problem that affects $44 \%$ of Malawian women aged 15-49 years, more so those who are 30 years and older ${ }^{(1)}$. Studies of anaemia among non-pregnant women of childbearing age are rare because most focus on expectant women, in whom anaemia and its complications are more prevalent. Data from such studies in sub-Saharan Africa have shown that some of the risk factors for anaemia among pregnant women include nutritional deficiencies (particularly $\mathrm{Fe}$ deficiency) and malaria parasitaemia ${ }^{(2,3)}$,elevated homocysteine concentrations $^{(4)}$, Schistosoma haematobium infection $^{(5)}$ and chronic inflammation ${ }^{(6)}$. Fe-deficiency anaemia, the primary cause of anaemia in sub-Saharan Africa, has enormous social and economic costs, which include reduced working capacity, economic stagnation, and maternal, prenatal and perinatal mortality ${ }^{(7)}$.

In an attempt to improve the health and nutrition status of women and children, a micronutrient and health (MICAH) programme was launched by World Vision Canada in 1995 , in five African countries (Ethiopia, Ghana, Malawi, Tanzania and Senegal). MICAH was implemented from 1996 to 2005 in Malawi, with a key focus on addressing anaemia in women and children, using a wide range of integrated interventions (Table 1$)^{(8)}$. We therefore conducted the present study to assess the impact of the MICAH programme on anaemia in non-pregnant Malawian women aged 15-49 years. The results are expected to inform the design of future public health nutrition programmes in Malawi. 
Table 1 Summary of the micronutrient and health (MICAH) programme objectives and interventions

\begin{tabular}{ll}
\hline Objective & \multicolumn{1}{c}{ Strategies } \\
\hline $\begin{array}{c}\text { To reduce anaemia and } \\
\text { Fe deficiency }\end{array}$ & $\bullet \begin{array}{l}\text { Fe supplementation } \\
\bullet \begin{array}{l}\text { Increase the intake and bioavailability } \\
\text { of Fe and related nutrients }\end{array}\end{array}$
\end{tabular}
of $\mathrm{Fe}$ and related nutrients

- Food fortification

- Dietary diversification and modification, with special emphasis on animal-source foods

- Prevention, control and treatment of malaria, hookworm and schistosomiasis infections
To reduce iodinedeficiency disorders
- lodised salt monitoring

- Education on the importance, use and storage of iodised salt

- Capacity building to monitor compliance to iodised salt legislation and monitoring imports, wholesale and retail salt

To build local capacity for delivery systems to improve micronutrient status

- Equipping laboratories
- Dissemination of a MICAH guide to harmonise operationalisation of the programme across the country

- Training staff on a wide range of micronutrients and health issues

- Influencing national policy or compliance to policy
Summary of interventions

- Weekly supplementation of $\mathrm{Fe}(60 \mathrm{mg})$ among children, and $\mathrm{Fe}$ $(60 \mathrm{mg})$ and folic acid $(400 \mu \mathrm{g})$ among non-pregnantt women of childbearing age, administered through village health volunteers, community health workers and traditional birth attendants

- Education on appropriate infant and young child feeding practices

- Dietary diversification to increase production and consumption of Fe-rich fruits, vegetables and small animals such as rabbits and chickens

- Introduction of community-based food fortification (Fe and multiple micronutrients, primarily maize flour or maize flour blended with legumes) piloted in eight local hammer mills $t$

- Increasing production and/or consumption of Fe-rich foods such as animal-source foods (goats, chickens, rabbits, guinea fowl); dark green leafy vegetables (amaranth (Amaranthus spp.), corchorus (Corchorus olitorius), okra (Hibiscus esculentus) and cat's whiskers (Cleome gynandra L.)); and fruits rich in vitamin $C$ (such as guavas, oranges and lemons) and $\beta$-carotene (such as mango and papaya)

- Provision of solar driers to encourage preservation of fruits and vegetables

- Provision of protected water through shallow wells and boreholes

- Education on construction of pit latrines

- Establishment of drug revolving funds to increase accessibility to community-level treatment for common illnesses (e.g. malaria)

- Treatment of malaria (using sulfadoxine-pyrimethamine), hookworms and schistosomiasis using national treatment guidelines

- Promotion of insecticide-treated bed netsł

- Prevention of HIV infections by disseminating HIV preventive messagesł

- Sponsoring quarterly salt monitoring meetings for all key partners

- Advocating for monitoring and enforcing of iodised salt legislation

- Educating communities and vendors on various aspects of iodised salt, e.g. storage

- Provision of equipment for monitoring salt at community level

- Capacity building at all levels

- Supporting creation of National MICAH Coordination within the Ministry of Health

- Advocating, through the Ministry of Health, compliance to legislation on the Salt lodization Act

- Supporting regular monitoring of iodised salt and enforcement of the Act

- Facilitating a strategy for commercial small-scale fortification of flour

Source: World Vision Canada (2006) ${ }^{(8)}$, p. 12.

tIn Malawi, pregnant women already receive $\mathrm{Fe}$ and folic acid supplements in all public health facilities throughout their pregnancy.

¥Evaluation of Phase I of the programme identified these gaps, which were implemented in Phase II.

\section{Materials and methods}

\section{Description of the MICAH programme to address anaemia}

The MICAH programme began in 1996 under the management of World Vision Malawi (WVM), implemented by eleven government and non-government (NGO) partners. The MICAH programme operated in nineteen project sites, within fourteen of Malawi's twenty-six districts and in all administrative regions of Malawi (North, Centre and South); reaching approximately 270000 beneficiaries, with indirect benefits extending to $4 \cdot 7$ million. The programme operated largely in rural areas, where people are mainly subsistence farmers and fishermen, growing crops of maize and legumes, with very little access to animal-source foods. The nineteen MICAH 
project areas were identified as a result of expressed needs by communities in those areas and selection criteria (e.g. lower access to health services, highest levels of malnutrition) determined by line ministries and partner NGO staff.

The comprehensive package to reduce anaemia included interventions to achieve three objectives: (i) improve Fe through increasing intake and bioavailability of $\mathrm{Fe}$ and related nutrients; (ii) reduce the prevalence of disease contributing to anaemia; and (iii) build capacity to implement programmes to address anaemia. Interventions to achieve the first objectives focused primarily on supplementation and dietary diversification and modification.

\section{Description of the surveys}

We used secondary data which were compiled from three cross-sectional surveys conducted in 2000 and 2004. Initially, data on women's $\mathrm{Hb}$ concentrations were available from the 1996 baseline survey and programme evaluations in 2000 and 2004. At baseline, the data were collected from pregnant women only, who were attending antenatal clinics. During the 2000 and 2004 evaluation surveys, however, data were collected from women at the community level, which included those who were not pregnant. Because of the small sample of pregnant women relative to those to those who were not pregnant, we excluded the former to leave 5422 non-pregnant women whose $\mathrm{Hb}$ concentrations were used in the current analysis (Fig. 1).

The 'MICAH areas' constituted populations that participated in the programme throughout its course. On the other hand, 'Comparison areas' received programme interventions until late 1999, when the interventions were withdrawn on recommendations of a mid-term evaluation to focus the full complement of the interventions in fewer areas rather than fewer interventions in more areas
(C MacDonald, personal communication, February 2007). These areas were used as comparison areas for the MICAH 2000 and 2004 surveys. The 1996 survey served as a common baseline for both MICAH and Comparison areas.

Primarily, the data were collected using structured household questionnaires which included questions related to: household demographic characteristics; agricultural activities; assets; water and sanitation; and knowledge and practices related to vitamin $\mathrm{A}, \mathrm{Fe}$, anaemia and iodine/ iodised salt ${ }^{(9)}$.

\section{Sampling}

As part of preparations for the surveys, project officers and community leaders conducted community sensitisation meetings in all areas. From a list of clusters (villages) and their population sizes in MICAH and Comparison areas, a probability proportional to population size sampling methodology was used to select clusters that would participate in the surveys. Using a household list, a sampling interval was devised and used to systematically random-sample the actual households to participate in the survey. The primary respondent was the main care provider of children in the household who was informed about the purpose of the survey and the different modules that the interview would cover, including laboratory requirements that the respondent and eligible children were expected to participate in. All interviews were conducted within the confinement of the respondents' homes, while blood samples were taken at central locations within the community, where mobile laboratories were set up. No incentives were given to those who participated in the surveys; however, women and children who were diagnosed with anaemia or parasitic infections received prompt treatment or referral to public health facilities. Data for 5422 women were used to assess the prevalence of anaemia in 2000 and 2004 (Fig. 1). 


\section{Measurement of $\mathrm{Hb}$ and malaria parasitaemia}

Mobile laboratory facilities were set up in the participating communities to collect $\mathrm{Hb}$ and malaria data. $\mathrm{Hb}$ was measured on-site from finger-prick blood samples using a portable haemoglobinometer (HemoCue ${ }^{\circledR}$; HemoCue AB, Ängelholm, Sweden), which is recommended for use in resource-constrained settings where laboratory facilities and highly trained technical expertise are not readily available ${ }^{(10)}$

Malaria parasites were also examined on-site by thick blood smears using Field's A and B staining methods ${ }^{(11)}$. All laboratory procedures were conducted by qualified laboratory technicians from selected health facilities in Malawi.

Considering that $\mathrm{Hb}$ increases in individuals with longterm residency at high elevations ${ }^{(12)}$, $\mathrm{Hb}$ values were corrected to sea level using estimates of the different altitudes of the survey areas ${ }^{(13)}$. Average altitudes ranged from $100 \mathrm{~m}$ to $1350 \mathrm{~m}$ above sea level; therefore, a factor of $2 \mathrm{~g} / \mathrm{l}$ was subtracted from all $\mathrm{Hb}$ values measured at $\geq 1000 \mathrm{~m}$, but no correction was applied for $\mathrm{Hb}$ values from lower altitudes ${ }^{(7)}$.

\section{Data analysis}

The data were entered on computer using Epi Info 6.04d (Centers for Disease Control and Prevention, Atlanta, GA, USA) and exported to the SPSS statistical software package version $14 \cdot 0$ (SPSS Inc., Chicago, IL, USA) for analysis. Data for the valid sample ( $n$ 5422) were examined for normality and homogeneity of variance, consistent with assumptions for running univariate analysis of variance (UNIANOVA). $\mathrm{Hb}$ was used as a dependent variable on four primary groups as follows: (i) $2000 \mathrm{MICAH}$ areas; (ii) 2000 Comparison areas; (iii) 2004 MICAH areas; and (iv) 2004 Comparison areas.

Malawi is divided into three administrative regions of the North, Centre and South. Therefore, Hb concentration and prevalence of anaemia were compared across the three administrative regions (North, Centre and South) of Malawi, through which the MICAH programme was also implemented and administered. Compared with the other two regions, the northern region has a relatively smaller population and population density, lower fertility levels and higher literacy levels, among other factors ${ }^{(13)}$. On the other hand, the southern region has the highest population density, with visibly more environmental degradation than the other two regions, whereas the central region dominates in crop production.

Graphical examination of the data using normality and Q-Q plots showed that the assumption of normality was met. $F$ statistics were computed using UNIANOVA in the general linear model to compare mean $\mathrm{Hb}$ values across the fixed factor levels. Because of lack of homogeneity of error variances of the outcome variable across groups, multiple comparisons of the mean $\mathrm{Hb}$ values were done using the Games-Howell post hoc test. International cutoff points were used to designate anaemia $(\mathrm{Hb}<120 \mathrm{~g} / \mathrm{l})$ and severe anaemia $(\mathrm{Hb}<70 \mathrm{~g} / 1)^{(7)}$. Proportional differences between any two groups were examined using the Pearson $\chi^{2}$ statistic in EpiTable, a program within Epi Info $6 \cdot 04 \mathrm{~d}$. To adjust for the probability proportional to population size methodology that was employed to select clusters during the surveys, the data were weighted using cluster populations provided by the National Statistical Office in Zomba, Malawi.

\section{Absolute and relative risk reductions}

Proportional differences in the prevalence of anaemia at national and regional levels were used to compute absolute and relative risk reductions and their corresponding odds ratios using the University of British Columbia clinical significance calculator, which is available online (http:// www.healthcare.ubc.ca/calc/clinsig.html).

\section{Ethics approval}

In Malawi, the MICAH programme received ethics clearance from the Ministry of Health, whereas approval to use the data set for further analysis was granted by the University of Guelph Research Ethics Board in Canada. At the community level, the surveys were conducted after verbal consent from traditional authorities in the participating clusters, and finally from the sampled household heads and/or respondents.

\section{Results}

\section{Characteristics of the sample}

Table 2 shows the characteristics of the women from MICAH and Comparison areas in the 2000 and 2004 surveys; they were comparable in age and gender of household heads. Mean (sE) Hb concentration was significantly higher in $2004 \mathrm{MICAH}$ areas $(121 \cdot 0(0 \cdot 4) \mathrm{g} / \mathrm{l})$ than in all other groups $(F=24 \cdot 2, \mathrm{df}=3, P<0 \cdot 001)$. In 2000 , significantly more women from MICAH areas had malaria parasitaemia $(22 \cdot 0 \%)$ compared with Comparison areas $\left(13 \cdot 1 \% ; \chi^{2}=40 \cdot 5, P<0 \cdot 0001\right)$. By 2004 , there were no significant differences in the prevalence of malaria parasitaemia between the two groups. As a result of the interventions, significantly more households from MICAH than Comparison areas had access to protected water sources during the rainy season; were raising livestock and growing fruit trees; were using bed nets to prevent malaria; were using toilets; and were receiving weekly $\mathrm{Fe} /$ folate supplements.

\section{Overall prevalence of anaemia}

Slightly more than half of the women were anaemic in 2000. By 2004, the prevalence of anaemia declined significantly in MICAH but not Comparison areas (Fig. 2). Severe anaemia $(\mathrm{Hb}<70 \mathrm{~g} / \mathrm{l})$ was very low, with prevalence of $1 \cdot 0 \%, 1 \cdot 3 \%, 0 \cdot 4 \%$ and $1 \cdot 1 \%$ in $2000 \mathrm{MICAH}$, 
Table 2 Characteristics of the sample of Malawian women and their households from the micronutrient and health programme (MICAH) and Comparison areas

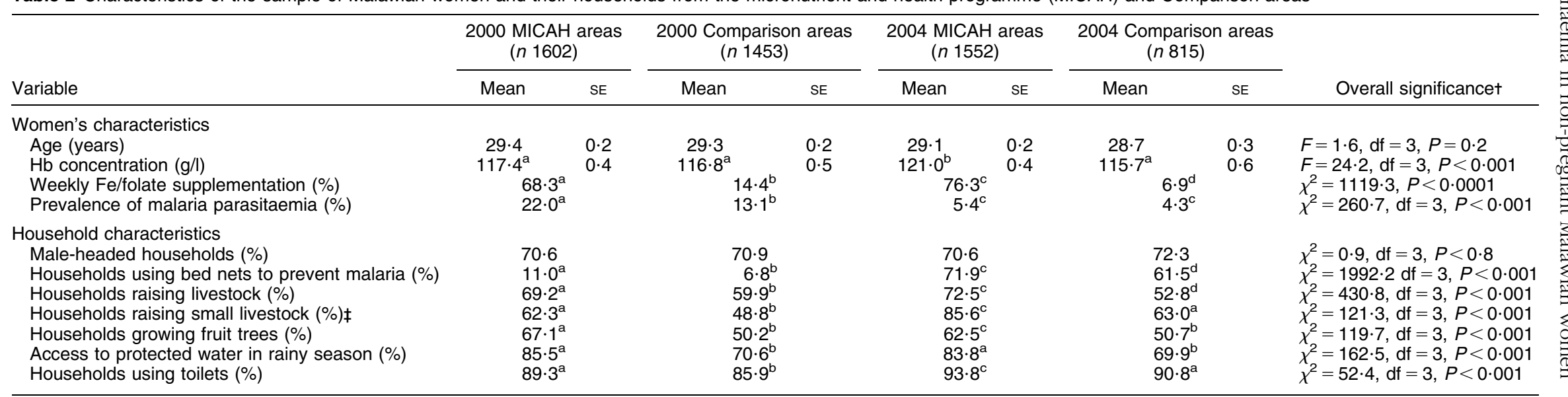

Except for the crude sample sizes, the results were weighted. Because of weighting, the sample sizes slightly changed for each of the variables.

Because of inequality of error variance, multiple comparisons of means were done using the Games-Howell post hoc test.

a,b,c,d Values within a row with unlike superscript letters were significantly different $(P<0.05)$ either using the $F$ test or the $\chi^{2}$ test.

tThe overall significance represents a global, non-specific indicator of significant differences existing or not among the four groups together. Further analyses were conducted to determine statistical differences between any two specific means (using the Games-Howell post hoc test) or proportions (using $\chi^{2}$ analysis).

$\ddagger$ The MICAH programme promoted small livestock, primarily rabbits, chickens, goats and guinea fowl. In the present study, small livestock included ducks and pigeons but excluded goats.

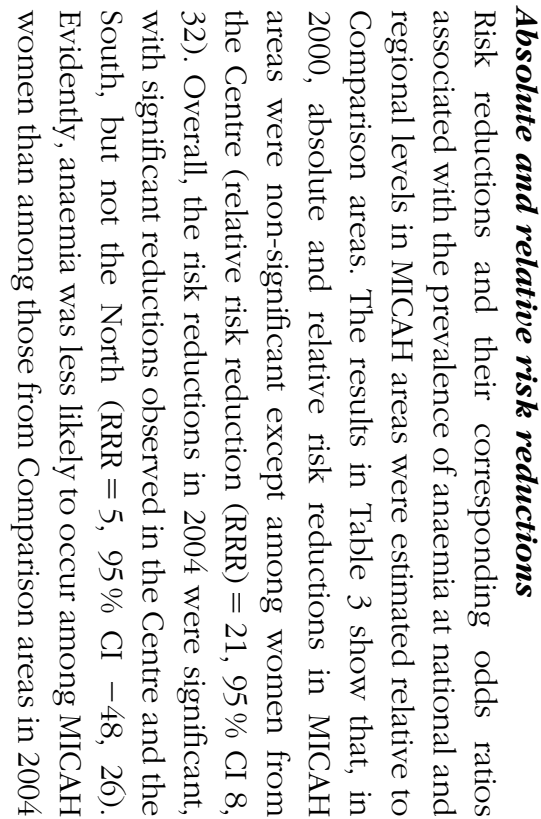

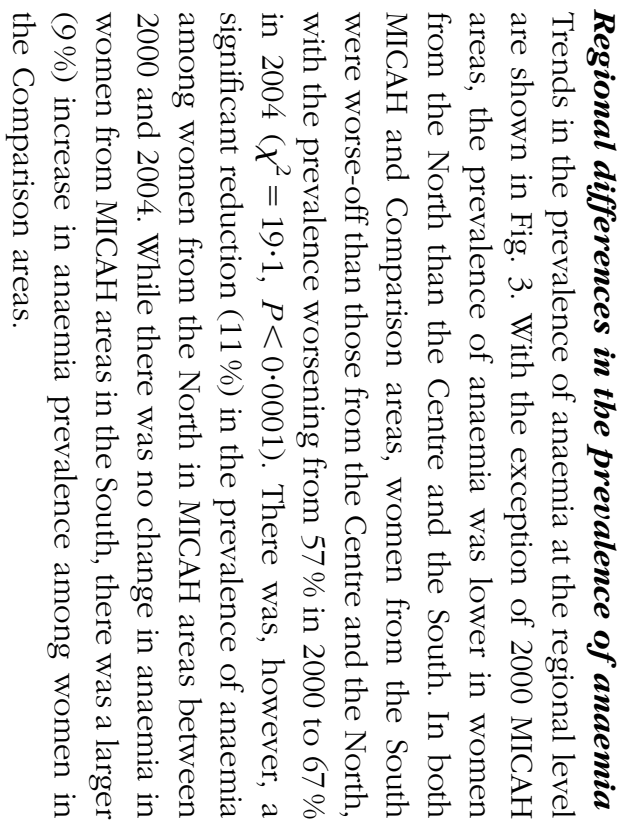

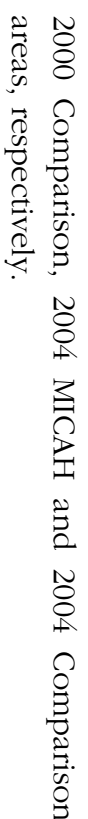

Prevalence of anaemia (\%)

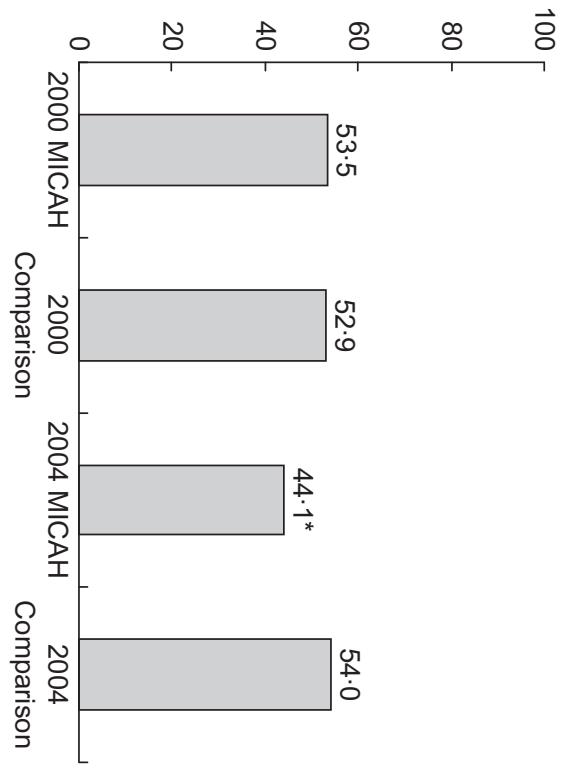




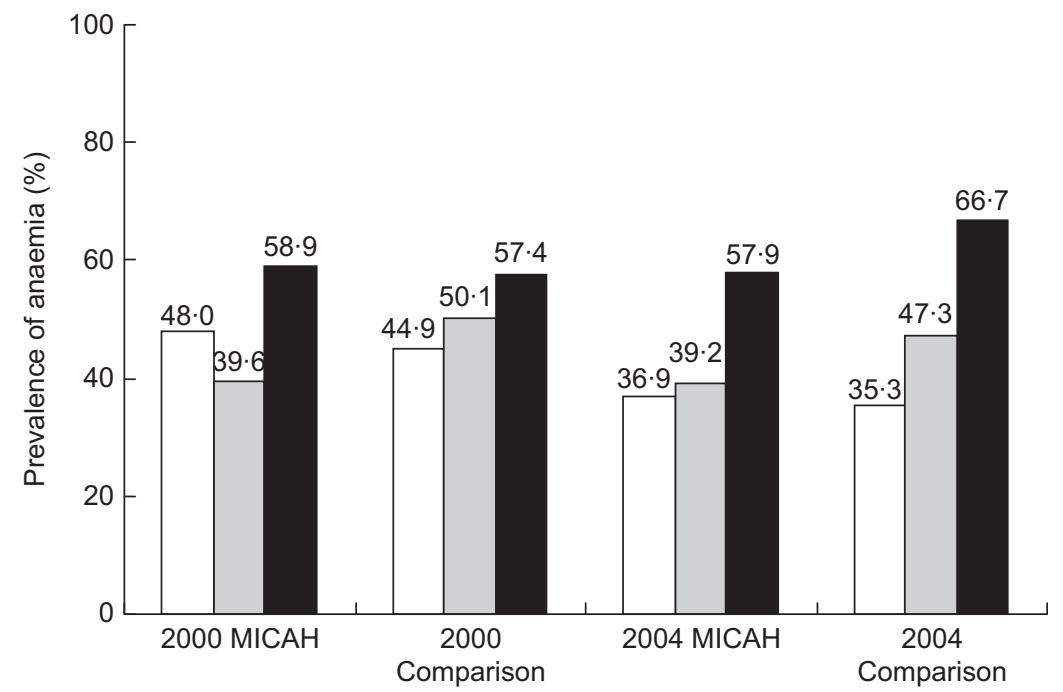

Fig. 3 Regional ( $\square$, North; $\square$, Centre; $\square$, South) disparities in the prevalence of anaemia among non-pregnant Malawian women aged 15-49 years from the micronutrient and health programme (MICAH) and Comparison areas. Results were weighted to adjust for the sampling methodology. $2000 \mathrm{MICAH}$ : North, $n$ 304; Centre, $n$ 283; South, $n 1018\left(\chi^{2}=37 \cdot 8, \mathrm{df}=2, P<0 \cdot 0001\right)$. 2000 Comparison: North, $n$ 107; Centre, $n$ 695; South, $n 611\left(\chi^{2}=10 \cdot 1\right.$, df $\left.=2, P<0 \cdot 006\right) .2004$ MICAH: North, $n$ 282; Centre, $n$ 853; South, $n 444\left(\chi^{2}=48 \cdot 7, \mathrm{df}=2, P<0 \cdot 0001\right)$. 2004 Comparison: North, $n$ 68; Centre, $n$ 425; South, $n 324\left(\chi^{2}=38 \cdot 2, \mathrm{df}=2\right.$, $P<0.0001)$

Table 3 Percentage absolute and relative risk reductions and odd ratios of the prevalence of anaemia in MICAH (micronutrient and health programme) areas relative to Comparison areas in 2000 and 2004

\begin{tabular}{|c|c|c|c|c|c|c|}
\hline $\begin{array}{l}\text { MICAH v. Comparison areas (overall) and by } \\
\text { region }\end{array}$ & $\begin{array}{l}\text { Absolute risk } \\
\text { reduction }\end{array}$ & $95 \% \mathrm{Cl}$ & $\begin{array}{l}\text { Relative risk } \\
\text { reduction }\end{array}$ & $95 \% \mathrm{Cl}$ & OR & $95 \% \mathrm{Cl}$ \\
\hline $2000 \mathrm{MICAH}$ (overall) v. Comparison (overall) & $0 \cdot 60$ & $-2 \cdot 96,4 \cdot 16$ & 1 & $-8,5$ & $1 \cdot 02$ & $0 \cdot 89,1 \cdot 18$ \\
\hline $\begin{array}{l}2000 \text { MICAH (regions) v. Comparison (regions) } \\
\text { North } \\
\text { Centre } \\
\text { South }\end{array}$ & $\begin{array}{r}3 \cdot 10 \\
10 \cdot 50 \\
1 \cdot 50\end{array}$ & $\begin{array}{c}-7 \cdot 90,14 \cdot 09 \\
3 \cdot 63,17 \cdot 37 \\
-3 \cdot 44,6 \cdot 44\end{array}$ & $\begin{array}{r}7 \\
21 \\
3\end{array}$ & $\begin{array}{c}-35,15 \\
8,32 \\
-12,6\end{array}$ & $\begin{array}{l}1 \cdot 13 \\
0 \cdot 65^{*} \\
1 \cdot 06\end{array}$ & $\begin{array}{l}0 \cdot 73,1 \cdot 76 \\
0 \cdot 49,0 \cdot 86 \\
0.87,1 \cdot 30\end{array}$ \\
\hline 2004 MICAH (overall) v. Comparison (overall) & $9 \cdot 90$ & $5 \cdot 70,14 \cdot 10$ & 18 & 11,25 & $0 \cdot 67^{*}$ & $0.57,0.80$ \\
\hline $\begin{array}{l}2004 \text { MICAH (regions) v. Comparison (regions) } \\
\text { North } \\
\text { Centre } \\
\text { South }\end{array}$ & $\begin{array}{l}1 \cdot 60 \\
8 \cdot 10 \\
8 \cdot 80\end{array}$ & $\begin{array}{r}-11 \cdot 15,14 \cdot 35 \\
2 \cdot 38,13 \cdot 82 \\
1 \cdot 86,15 \cdot 74\end{array}$ & $\begin{array}{r}5 \\
17 \\
13\end{array}$ & $\begin{array}{r}-48,26 \\
5,28 \\
3,23\end{array}$ & $\begin{array}{l}1 \cdot 07 \\
0 \cdot 72^{*} \\
0.69^{*}\end{array}$ & $\begin{array}{l}0.62,1.86 \\
0.57,0.91 \\
0.51,0.92\end{array}$ \\
\hline
\end{tabular}

Baseline data for non-pregnant women were unavailable because the survey targeted pregnant women only.

Results are based on weighted data.

${ }^{*}$ Significant association $(P<0 \cdot 05)$.

$(\mathrm{OR}=0 \cdot 67,95 \% \mathrm{CI} 0 \cdot 57,0 \cdot 80)$, but not in $2000(\mathrm{OR}=$ $1 \cdot 02,95 \%$ CI $0 \cdot 89,1 \cdot 18)$.

\section{Discussion}

Population-based studies on anaemia in non-pregnant African women are rare, partly due to the priority accorded to pregnant women, who are more vulnerable than non-pregnant women ${ }^{(14)}$. The present study fills an important gap in understanding the prevalence of anaemia in women of childbearing age in rural areas in Malawi, in addition to showing the effect of an integrated, community-based, public health nutrition programme on anaemia. Because the MICAH baseline survey exclusively targeted pregnant women, there is a lack of comparable data to demonstrate how the prevalence of anaemia may have changed from the baseline in 1996 to the end of the programme in 2004.

As shown in Table 2 and Fig. 2, there were no significant differences in $\mathrm{Hb}$ concentration and anaemia prevalence between MICAH and Comparison areas in 2000, suggesting that the MICAH programme did not have a significantly unique impact on anaemia during Phase I. Considering that Comparison areas received some programme interventions, it is possible that the prevalence in 2000, shown in Fig. 2, reflects a positive impact of the MICAH programme in those areas; however, this cannot be claimed with certainty 
because of the lack of comparable baseline data, which could have shown the rates of anaemia before the MICAH interventions. According to global guidelines, prevalence of anaemia in excess of $40 \%$ denotes a significant public health problem $^{(7)}$. Therefore, anaemia constituted a public health problem among women of childbearing age in MICAH and Comparison areas at the end of both Phase I (1996-2000) and Phase II (2000-2004) of the programme (Fig. 2).

Importantly, over the four years of Phase II, a significant increase in $\mathrm{Hb}$ concentration to just above the cut-off value in MICAH areas (mean (sE): $121 \cdot 0(0 \cdot 4) \mathrm{g} / \mathrm{l})$ resulted in an $18 \%$ reduction from the 2000 levels of prevalence of anaemia while there was no change in Comparison areas. This suggests that the MICAH programme was effective in reducing anaemia among the women in Phase II, and while levels still indicate a severe health problem, the progress is programmatically important. The significant relative risk reduction of $18 \%$ observed in 2004 MICAH areas, as opposed to the dismal relative risk reduction in 2000, suggests that in women of childbearing age, the MICAH programme was more effective during Phase II than in Phase I. This may suggest that among non-pregnant women, longterm rather than short-term programmes are more likely to have a significant impact in reducing anaemia. Indeed, many of the key interventions of the comprehensive package of the MICAH programme require time for implementation at scale. Moreover, Phase I implementation began only in late 1998, as essential programme set-up including baseline assessment (1996), establishing a multi-sectoral programme with multiple institutional partners, procuring supplies and equipment, building capacity at all levels, and engaging communities in designing contextually appropriate interventions (1997), were required in the first several years. The greater effectiveness in Phase II may also have been partially due to the refocusing of resources on the comprehensive package of interventions in fewer areas, rather than providing fewer interventions to more communities (Phase I), based on recommendation from the external 'mid-term' evaluation recommendations in 1999.

The significant decrease in anaemia in the MICAH areas from 2000 to 2004 is attributed to the comprehensive package of interventions for anaemia prevention and control, as described previously, and it is likely there would not have been positive results from only one or two isolated interventions given the multifaceted aetiology of anaemia. It is likely that the high coverage of weekly $\mathrm{Fe} /$ folate supplementation was one of the key interventions contributing to the decrease in anaemia, given the large difference in coverage in the MICAH and Comparison areas. However, further study is required to determine the relative contribution and costs of the various interventions and/or groups of interventions to achieving the reduction in anaemia.

According to Table 3, the increase in overall relative risk reduction could be attributed mostly to improvements in the South where the relative risk reduction increased from $3 \%$ in 2000 to $13 \%$ in 2004, while for the Centre and the North it depicted modest changes between the two surveys. This is also evidenced by the regional trends in Fig. 3, which showed a significant increase in the prevalence of anaemia in the South, from $57 \%$ in 2000 to $67 \%$ in 2004 . This suggests that the deterioration of anaemia in the Comparison areas was prevented from occurring in the MICAH areas due to the comprehensive package of interventions. Similarly, the significantly lower prevalence of anaemia in the Centre in 2004 MICAH relative to Comparison areas contributed to the significant relative risk reduction in the Centre.

Malawi's northern region has several socio-economic advantages over other regions because it has a relatively smaller population and population density, a lower fertility rate and higher literacy level, among other factors $^{(13)}$. These characteristics may have a profound intergenerational effect on nutrition and health, thereby contributing to the comparatively low prevalence of anaemia that was observed in the North. This suggests that there is a need for region-specific design and implementation of nutrition programmes in Malawi. While being administratively convenient, blanket national programmes are less likely to be effective in the South and the Centre where anaemia among non-pregnant women is a more prevalent problem than in the North. The results also point to the need for region-specific studies to determine the most important predictors of anaemia and other nutritional deficiencies, so that appropriate localised interventions can be formulated as much as possible.

The significant reduction in prevalence of malaria in both MICAH and Comparison areas (Table 3) may be attributed to Roll Back Malaria and the National Malaria Control Programme, which Malawi has been implementing since the early $2000 \mathrm{~s}^{(1)}$. The two initiatives aim to reduce the incidence and prevalence of malaria through use of insecticide-treated mosquito nets; prompt and effective treatment of malaria within $24 \mathrm{~h}$ of onset of illness; improved malaria case management; and intermittent preventive treatment of pregnant women with sulfadoxinepyrimethamine. Since these are national programmes, it is highly likely that they contributed to reduction in malaria irrespective of being MICAH or Comparison areas.

\section{Strengths and limitations of the study}

The MICAH programme was long-term, covering some of the poorest areas in Malawi, and reaching heterogeneous populations from a cross-section of cultural, ecological and socio-economic backgrounds; hence, the results can be extrapolated to rural areas across Malawi. The impact of the programme on anaemia in women makes MICAH a potential public health nutrition model for combating anaemia among non-pregnant women in Malawi.

However, the lack of baseline data for non-pregnant women made it impossible to evaluate how the prevalence 
of anaemia may have changed between the baseline survey in 1996 and the evaluation of MICAH Phase I in 2000. Since the Comparison areas had participated in programme interventions until 1999, it is possible that the programme effects were sustained to the end of MICAH Phase I in 2000, thereby masking the true prevalence of anaemia in the Comparison areas. In the current study, non-pregnant women were identified by asking female respondents whether or not they were pregnant. This may not, however, be a reliable method because women may conceal their pregnancy until it is visible for cultural reasons.

\section{Conclusions}

The MICAH programme was an effective public health nutrition intervention using an integrated package of interventions (increasing dietary $\mathrm{Fe}$, decreasing diseases and building capacity) that significantly reduced the prevalence of anaemia among non-pregnant Malawian women between 2000 and 2004. The MICAH model can be used in future public health nutrition interventions to reduce the high prevalence of anaemia in Malawian women. The results achieved by MICAH are programmatically important, but anaemia in non-pregnant Malawian women remains unacceptably high, and continued efforts need to be made to reduce the prevalence of anaemia in Malawian women.

\section{Acknowledgements}

Sources of funding: The MICAH programme was a joint programme of World Vision Canada and its partners in Africa, with funding from the Canadian International Development Agency and World Vision Canada. The data used in the current analysis were provided by World Vision Canada. At the time of writing the manuscript, the lead author was pursuing doctoral studies in Applied Human Nutrition at the University of Guelph in Canada under the Canadian Commonwealth Scholarship Programme. We acknowledge the programme manager who led the implementation of the field programme: Ms Rose H Namarika. The contributions of many other individuals and institutions that supported the implementation and evaluation of the MICAH programme are also gratefully acknowledged, especially the participating members of the MICAH communities. The government partners were Ministries of Health and Population (MOHP), Agriculture and Irrigation (MOAI), and the Community Health Sciences Unit (CHSU). Non-governmental partners included AFRICARE, Ekwendeni Mission Hospital, Emmanuel International, Domasi Community Nutrition Project, International Eye Foundation,
Mua Mission Hospital, St Gabriel's Mission Hospital and World Vision Malawi. Conflict of interest: We declare no conflict of interest. Author contributions: A.A.K. (principal investigator) wrote a proposal for further examination of the project data; drafted an agreement between the University of Guelph and World Vision Canada; applied for ethics approval; received data sets from World Vision Canada; cleaned and merged the data sets; analysed the data; and drafted the manuscript. C.M. co-designed the micronutrient and health (MICAH) programme; supervised data cleaning and merging; supervised data analysis; and edited the draft manuscript. J.R.S. proposed further examination of the project data; co-drafted an agreement between the University of Guelph and World Vision Canada; co-applied for ethics approval; supervised data cleaning and merging; supervised data analysis; and edited the draft manuscript.

\section{References}

1. National Statistical Office (2005) Malawi Demographic and Health Survey 2004. Zomba, Malawi: NSO.

2. Verhoeff FH, Brabin BJ, Chimsuku L et al. (1999) An analysis of the determinants of anaemia in pregnant women in rural Malawi - a basis for action. Ann Trop Med Parasitol 93, 119-133.

3. Marchant T, Armstrong Schellenberg JR, Edgar $\mathrm{T}$ et al. (2002) Anaemia during pregnancy in southern Tanzania. Ann Trop Med Parasitol 96, 477-487.

4. Vanderjagt DJ, Brock HS, Melah GS et al. (2007) Nutritional factors associated with anaemia in pregnant women in northern Nigeria. J Health Popul Nutr 25, 75-81.

5. Ayoya MA, Spiekermann-Brouwer GM, Traoré AK et al. (2006) Determinants of anemia among pregnant women in Mali. Food Nutr Bull 27, 3-11.

6. van den Broek NR \& Letsky EA (2000) Etiology of anemia in pregnancy in south Malawi. Am J Clin Nutr 72, 1 Suppl., 247S-256S

7. World Health Organization (2001) Iron Deficiency Anaemia: Assessment, Prevention and Control. A Guide for Programme Managers. Geneva: WHO.

8. World Vision Canada (2006) Improving Nutrition of Women and Children: The MICAH Program. Mississauga, ON: World Vision Canada.

9. World Vision Canada (2001) Design and Implementation of Nutrition Surveys. Excerpt from the MICAH Guide. Mississauga, ON: World Vision Canada.

10. Johns WL \& Lewis SM (1989) Primary health screening by haemoglobinometry in a tropical community. Bull World Health Organ 67, 627-633.

11. Reilly JT, Bain BJ, Amos R et al. (1997) The laboratory diagnosis of malaria. Clin Lab Haematol 19, 165-170.

12. Dirren H, Logman MH, Barclay DV et al. (1994) Altitude correction for hemoglobin. Eur J Clin Nutr 48, 625-632.

13. National Statistical Office \& International Food Policy Research Institute (2002) Malawi: An Atlas of Social Statistics. Zomba, Malawi: NSO \& IFPRI.

14. United Nations Administrative Committee on Coordination/Standing Committee on Nutrition (2000) Fourth Report on the World Nutrition Situation. Geneva: UN ACC/SCN. 